\title{
Rectal Obstruction, CTCAE
}

National Cancer Institute

\section{Source}

National Cancer Institute. Rectal Obstruction, CT CAE. NCI Thesaurus. Code C57864.

A disorder characterized by blockage of the normal flow of the intestinal contents in the rectum. 